\title{
Six novel mutations in the arginine vasopressin gene in 15 kindreds with autosomal dominant familial neurohypophyseal diabetes insipidus give further insight into the pathogenesis
}

\author{
Jane H Christensen ${ }^{1}$, Charlotte Siggaard ${ }^{2}$, Thomas J Corydon ${ }^{3}$, Luisa deSanctis ${ }^{4}$, \\ Laszlo Kovacs $^{5}$, Gary L Robertson ${ }^{6}$, Niels Gregersen ${ }^{7}$ and Søren Rittig ${ }^{\star 2}$
}

\footnotetext{
${ }^{1}$ Pediatric Research Laboratory, Aarhus University Hospital, Skejby Sygehus, Aarhus, Denmark; ${ }^{2}$ Department of Pediatrics, Aarhus University Hospital, Skejby Sygehus, Aarhus, Denmark; ${ }^{3}$ Department of Human Genetics, University of Aarhus, Aarhus, Denmark; ${ }^{4}$ Department of Pediatrics, University of Torino, Torino, Italy; ${ }^{5}$ Comenius University Medical School, Comenius University, Bratislava, Slovakia; ${ }^{6}$ Department of Medicine, Northwestern University Medical School, Chicago, IL, USA; ${ }^{7}$ Research Unit for Molecular Medicine, Aarhus University Hospital, Skejby Sygehus, Aarhus, Denmark
}

Autosomal dominant familial neurohypophyseal diabetes insipidus (adFNDI) is caused by postnatal arginine vasopressin (AVP) deficiency resulting from mutations in the AVP gene encoding the AVP preprohormone. To advance the understanding of adFNDI further, we have searched for mutations in the AVP gene in 15 unrelated kindreds in which diabetes insipidus appeared to be segregating. In nine kindreds, seven different previously described mutations were identified. In each of the other six kindreds, unique novel mutations were identified. Two of these $(225 \mathrm{~A}>\mathrm{G}$ and $227 \mathrm{G}>\mathrm{A})$ change a nucleotide in the translation initiation codon of the signal peptide, whereas the other four (1797T $>C, 1884 G>A, 1907 T>G$, and $2112 \mathrm{C}>\mathrm{G}$ ) predict amino-acid substitutions in the neurophysin II moiety of the AVP prohormone, namely V67A (NP36), G96D (NP65), C104G (NP73), and C116W (NP85). Among these, the mutation predicting the V67A (NP36) substitution is remarkable. It affects a region of the neurophysin II not affected by any other mutations, produces only a minor change, and its inheritance suggests an incomplete penetrance. Our findings both confirm and further extend the mutation pattern that has emerged in adFNDI, suggesting that the mutations affect amino-acid residues known or reasonably presumed to be important for the proper folding and/or dimerization of the neurophysin II moiety of the AVP prohormone.

European Journal of Human Genetics (2004) 12, 44-51. doi:10.1038/sj.ejhg.5201086

Published online 3 December 2003

Keywords: diabetes insipidus; AVP gene; mutation; neurohypophyseal; autosomal dominant; neurophysin II

${ }^{*}$ Correspondence: Dr S Rittig, Department of Pediatrics, Aarhus University Hospital, Skejby Sygehus, Brendstrupgaardsvej, DK-8200 Aarhus N, Denmark. Tel: + 45894967 73; Fax: + 45894960 11; E-mail: rittig@iekf.au.dk

Received 1 April 2003; revised 10 July 2003; accepted 18 July 2003
Introduction

Autosomal dominant familial neurohypophyseal diabetes insipidus (adFNDI) is a rare inherited disease (OMIM: $192340,125700)$ that appears to be largely, if not completely, penetrant. ${ }^{1}$ It usually presents several months to years after birth and is clinically characterized by 
polyuria accompanied by persistently increased thirst and/ or fluid intake. ${ }^{2}$ The underlying cause is a deficient neurosecretion of the antidiuretic hormone, arginine vasopressin (AVP), which in most cases, but not all, is so severe that even an intense stimulus like hypertonic dehydration fails to elicit enough AVP to achieve urine concentration. In the few cases in which it has been studied by repetitive fluid deprivation tests, AVP secretion appears to diminish progressively during early childhood. ${ }^{3,4}$ Autopsy studies in a few adFNDI patients have shown atrophy of the neurohypophysis and a decreased number of magnocellular neurons in the supraoptic and paraventricular nuclei of the hypothalamus, ${ }^{4-7}$ suggesting that the disease is due to selective degeneration of the cells that normally produce AVP.

Until now, adFNDI has been linked to 42 different mutations in the AVP gene (GenBank: M11166) ${ }^{8-15}$ The AVP gene is located on chromosome 20 (20p13) and contains three exons encoding the AVP pre-prohormone comprising a signal peptide, AVP, neurophysin II (NP), and a C-terminal glycopeptide, copeptin. ${ }^{16}$ Most adFNDI mutations are deduced to affect amino-acid residues known or reasonably presumed to be important for the proper folding and/or dimerization of the NP moiety of the AVP prohormone. ${ }^{17,18}$ It has been proposed that the dominant-negative effect exerted by the mutations is due to the production of a mutant hormone precursor that fails to fold and/or dimerize properly in the endoplasmic reticulum (ER) and, as a consequence, is retained by the ER protein quality control machinery, ${ }^{19-21}$ resulting in the cytotoxic accumulation of mutant protein in the neurons. $^{22,23}$ This hypothesis takes into account the characteristic severity of the AVP deficiency in adFNDI, the delayed and possible progressive nature of its development, and the evidence of selective degeneration of the AVP-producing neurons. It is supported, at least partly, by heterologous expression experiments in cell cultures or transgenic animals, ${ }^{22-31}$ but the hypothesized role of cytotoxicity in adFNDI remains unclear.

In the present study, the identification of six novel and seven different previously described mutations in the AVP gene in 15 apparently unrelated kindreds in which diabetes insipidus appeared to be segregating further advances the understanding of adFNDI.

\section{Materials and methods Subjects}

We studied 42 members of 15 kindreds in which diabetes insipidus appeared to be segregating (Tables 1 and 2). All kindreds were Caucasian, except for one Asian (Table 1, kindred 3) and their nationalities were as indicated. The kindreds were diagnosed and/or referred either by us or by those cited elsewhere (see Acknowledgements). AdFNDI was diagnosed in one or more family members in 13 of the 15 kindreds studied. In 10 of these (Tables 1 and 2), a family history of the disease was described by a pedigree covering the indicated number of generations and in the other three, a family history of adFNDI was well known as reported by the referring physician, but not described by a pedigree. In one of the remaining two kindreds (Table 1, kindred 1), no family history of adFNDI was reported. In the other (Table 1, kindred 3), adFNDI was diagnosed but the inheritance pattern was atypical in that, the proband apparently inherited the disease through his affected mother, although allegedly neither of his maternal grandparents had a history of polyuria, and even though a brother of the maternal grandmother was also affected. In five kindreds (Table 1, kindred 6 and Table 2, kindreds 7-9 and 12), it was reported that the diagnosis of adFNDI was confirmed in at least one member by a fluid deprivation or hypertonic saline infusion test. Magnetic resonance imaging was performed on the proband of kindred 6 , showing a normal adenohypophysis as well as pituitary stalk and

Table 1 Six novel mutations in the AVP gene identified in kindreds with adFNDI

\begin{tabular}{|c|c|c|c|c|c|c|c|c|c|c|}
\hline \multirow[b]{2}{*}{$\begin{array}{l}\text { Kindred } \\
\text { number }\end{array}$} & \multirow[b]{2}{*}{ Nationality } & \multirow[b]{2}{*}{$\begin{array}{l}\text { Number of } \\
\text { generations }\end{array}$} & \multirow[b]{2}{*}{ Exon } & \multirow[b]{2}{*}{$\begin{array}{l}\text { Mutation } \\
\text { DNA level }^{a}\end{array}$} & \multirow{2}{*}{$\begin{array}{l}\text { Deduced } \\
\text { consequence } \\
\text { protein level }^{b}\end{array}$} & \multirow[b]{2}{*}{ Peptide ${ }^{c}$} & \multirow[b]{2}{*}{$\begin{array}{l}\text { Restriction } \\
\text { endonuclease }\end{array}$} & \multicolumn{3}{|c|}{ Mutation found in } \\
\hline & & & & & & & & Affected & $\begin{array}{c}\text { Not } \\
\text { studied }^{d}\end{array}$ & $\begin{array}{c}\text { Not } \\
\text { affected }\end{array}$ \\
\hline 1 & Belgian & $-{ }^{e}$ & 1 & $225 \mathrm{~A}>\mathrm{G}$ & M1_T4del & SP-19-16 & Fokl & $1 / 1$ & $0 / 0$ & $0 / 0$ \\
\hline 2 & Czech & 4 & 1 & $227 G>A$ & $\mathrm{M1}^{-} \mathrm{T}$ 4del & SP-19-16 & Fokl & $3 / 3$ & $0 / 0$ & $0 / 0$ \\
\hline 3 & American & $4^{f}$ & 2 & $1797 \mathrm{~T}>\mathrm{C}$ & V67̄A & NP36 & Acil & $1 / 1$ & $1 / 1$ & $0 / 0$ \\
\hline 4 & Swedish & 2 & 2 & $1884 G>A$ & G96D & NP65 & Haelll & $4 / 4$ & $1 / 1$ & $0 / 0$ \\
\hline 5 & Czech & 5 & 2 & $1907 \mathrm{~T}>\mathrm{G}$ & C104G & NP73 & Hincll9 & $3 / 3$ & $0 / 0$ & $1 / 3$ \\
\hline 6 & Italian & 2 & 3 & $2112 C>G$ & C116W & NP85 & Hhal & $2 / 2$ & $0 / 0$ & $0 / 0$ \\
\hline
\end{tabular}

\footnotetext{
${ }^{\mathrm{a}}$ Numbers refer to the gDNA sequence of the AVP gene, GenBank accession number M11166. Nomenclature according to recommendations. ${ }^{55,56}$

${ }^{b}$ Numbers refer to codons (initiator methionine $=$ codon 1). Nomenclature according to recommendations. ${ }^{55,56}$

${ }^{\mathrm{C}}$ Numbers refer to the position in the individual peptides originating from the AVP pre-prohormone. SP, signal peptide; NP, neurophysin II.

dNo clinical studies performed.

e No family history of adFNDI reported.

fUnusual inheritance pattern (see Materials and methods).

${ }^{9}$ Recognition site created by an exon 2 antisense primer with mismatched nucleotide.
} 
Table 2 Seven recurrent mutations in the AVP gene identified in kindreds with adFNDI

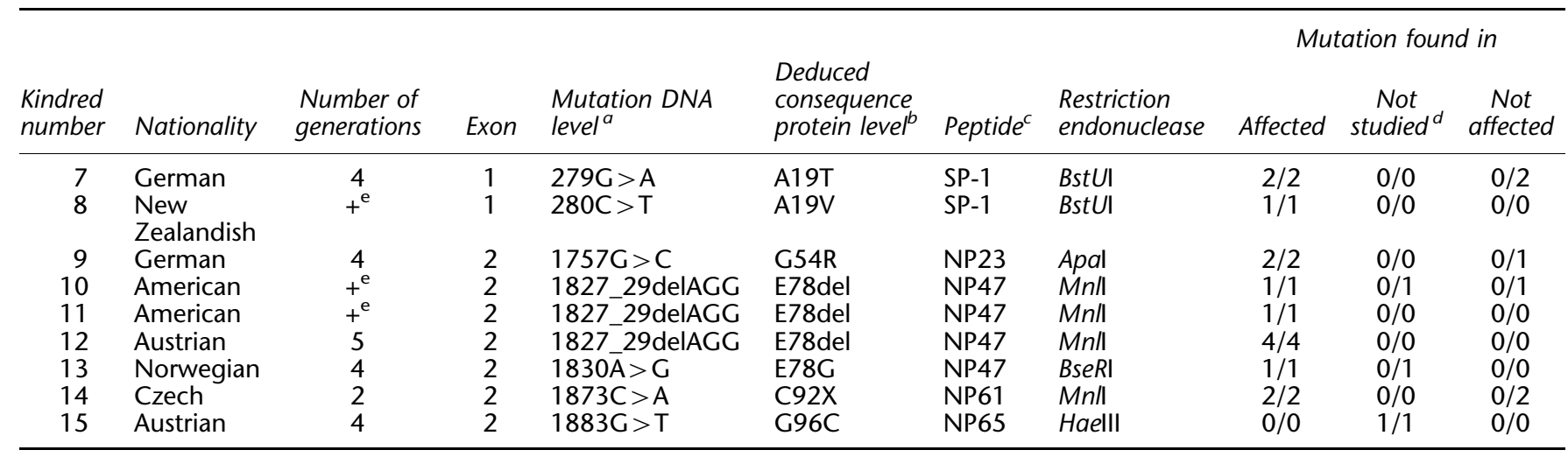

a-d See the notes of Table 1 .

epositive family history of adFNDI by referring physician, pedigree not available.

optical chiasma, whereas only a thin hyperintense signal of the posterior pituitary on T1-weighted images was evident. All the studies were approved by the appropriate institutional review boards.

\section{Laboratory procedures}

Samples of purified genomic DNA or whole blood were shipped for analysis to our laboratory. In the latter case, genomic DNA was extracted from the buffy coat of peripheral leukocytes either as described previously ${ }^{17}$ or by the AquaPure Genomic DNA Isolation Kit (Bio-Rad Laboratories, Hercules, CA, USA). All three exons of the AVP gene were PCR amplified separately using 31 base pair flanking primers. The primer sequences and cycle conditions were as previously described. ${ }^{17}$ The nucleotide sequences were determined by automated dye-terminator sequencing either on isolated single-stranded biotinylated sense and antisense strands using T7 DNA Polymerase (Sequenase) and the nonbiotinylated primers as described previously $^{17}$ or directly on both strands using either dRhodamine or BigDye ${ }^{\mathrm{TM}}$ Terminator Cycle Sequencing Kits with AmpliTaq ${ }^{\circledR}$ DNA Polymerase, FS (fluorescent sequencing). The sequencing products were analyzed on an ABI PRISM ${ }^{\circledR} 377$ DNA Sequencer (Applied Biosystems, Foster City, CA, USA). Mutation detection assays based on restriction endonuclease digestion of the PCR products were performed as described previously. ${ }^{17}$ The enzymes were selected to recognize specifically either the nucleotide sequence containing the mutation in question or the corresponding normal AVP gene sequence, whereby digestions generated mutation-dependent cleavage products. One mutation $(1907 \mathrm{~T}>\mathrm{G})$ did not involve a recognition site of any commercial available restriction endonuclease, hence the exon 2 antisense primer was exchanged with a 5'-CCCCGCCGCGCACCGTCGTTGCAGT-3' (position 1908-1932 of the AVP gene) antisense primer with a mismatched nucleotide (underlined) to create a mutation- dependent recognition site for the HincII restriction endonuclease (New England Biolabs, Inc., MA, USA).

\section{Results}

In order to identify the possible adFNDI-causing mutations, the three exons of the AVP gene were PCR amplified and DNA sequencing analysis was performed in one or more affected members of 15 kindreds in whom diabetes insipidus appeared to be segregating. The results are summarized in Tables 1 and 2. In all the cases, a mutation was found in the coding region of the AVP gene' the mutation in question was the only one identified, it affected only one allele, and was evident on both the sense and antisense strand. When only one affected individual was analyzed, the presence of the mutation was confirmed on a second PCR product. In order to verify the sequencing results and in some cases to screen for specific mutations in family members not subjected to DNA sequencing, PCR amplified exons were subjected to digestion with restriction endonucleases (Tables 1 and 2).

All the mutations identified predict a change in the amino-acid sequence of the AVP pre-prohormone. In each of the six kindreds (Table 1, kindreds 1-6), unique novel mutations were identified. Two of these mutations, $225 \mathrm{~A}>\mathrm{G}$ and $227 \mathrm{G}>\mathrm{A}$ (Table 1, kindred 1 and 2 , respectively), change a nucleotide in the translation initiation codon of the AVP pre-prohormone signal peptide. The four other novel mutations, $1797 \mathrm{~T}>\mathrm{C}$, $1884 \mathrm{G}>\mathrm{A}, 1907 \mathrm{~T}>\mathrm{G}$, and $2112 \mathrm{C}>\mathrm{G}$ (Table 1, kindreds $3,4,5$, and 6 , respectively), all predict amino-acid substitutions in the NP moiety of the AVP prohormone, namely V67A (NP36), G96D (NP65), C104G (NP73), and C116W (NP85), where the numbers in the parentheses refer to the amino-acid position in NP.

In the other nine kindreds investigated (Table 2, kindred 7-15), seven different previously described mutations were 
identified. One mutation, namely 1827_29delAGG (Table 2, kindreds 10-12), was identified in three kindreds (two American and one Austrian) with no known relationship to each other or to the other two adFNDI kindreds (Japanese and American) in which the same mutation has been identified previously. ${ }^{17,32}$ The other six recurrent mutations were identified in only one kindred each (Table 2, kindreds 7-9 and 13-15). None of these kindreds had any known relationship to the kindreds in which the same mutations have been described previously, namely the 279G > A (A19T) mutation identified in four American, a Japanese, a Danish, a Spanish, and a Brazilian kindred, $^{3,15,17,33-36}$ the $280 \mathrm{C}>\mathrm{T}$ (A19V) mutation identified in two American, a Lebanese, a German, and a Japanese kindred, ${ }^{10,11,17,37}$ the $1757 \mathrm{G}>\mathrm{C}$ (G54R) mutation identified in a German and an American kindred, ${ }^{13,38}$ the $1830 \mathrm{~A}>\mathrm{G}$ (E78G) mutation identified in an English kindred, ${ }^{17}$ the $1873 \mathrm{C}>\mathrm{A}(\mathrm{C} 92 \mathrm{X})$ mutation identified in a

a

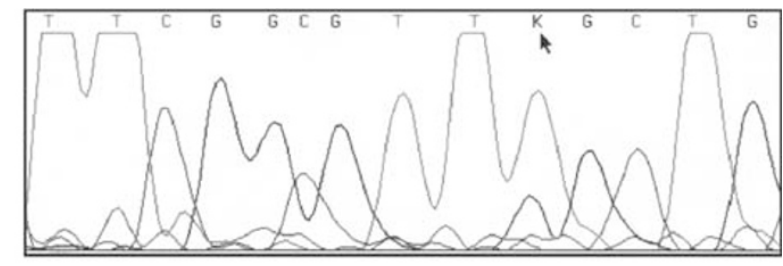

b

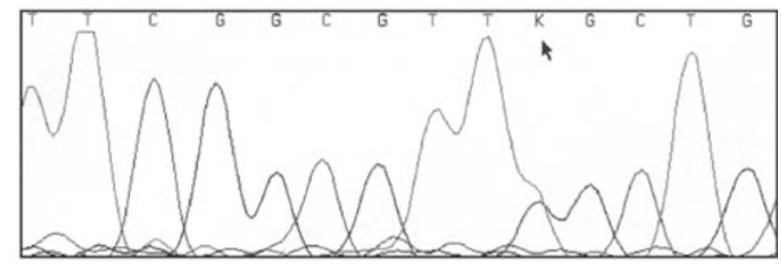

C

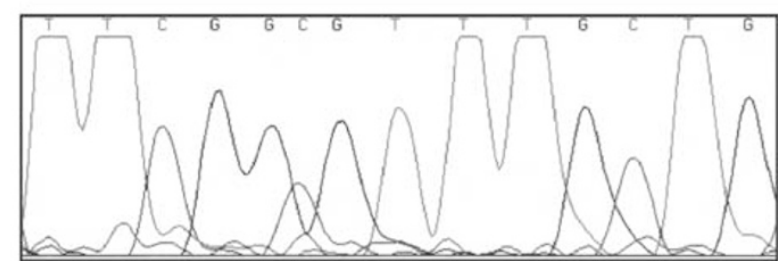

Figure 1 Automated dye-terminator sequencing of the AVP gene in members of a kindred in which adFNDI appeared to be segregating (kindred 5). All three exons of the AVP gene were PCR amplified from purified genomic DNA, and their nucleotide sequences were determined by automated dye-terminator sequencing. Panels a-c, sections of the electropherograms obtained by the sequencing of exon 2 from a clinically unaffected child at risk for inheriting adFNDI ( $a$, sense strand and $\mathbf{b}$, antisense strand) and from an unaffected member of the same kindred (c, sense strand). A 1907T $>G$ nucleotide substitution was identified in one allele of the AVP gene in the subject at risk (arrows), in two other clinically affected family members (not shown), but not in an unaffected member of the same kindred. Thus, although still clinically unaffected, it is evident that the subject at risk for inheriting adFNDI is indeed a carrier of the mutation.

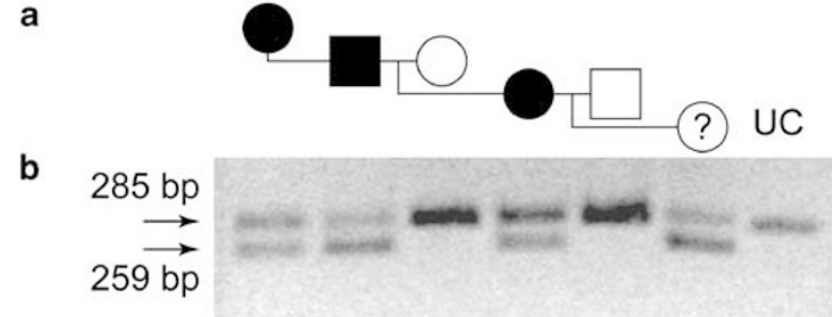

Figure 2 Restriction endonuclease digestion analysis of PCR amplified exon 2 from the AVP gene in members of a kindred in which adFNDI appeared to be segregating (kindred 5). Since the 1907T > G mutation identified in the kindred do not create or eliminate a recognition site of any commercially available restriction endonuclease, exon 2 was PCR amplified using an antisense primer carrying a mismatched nucleotide to create a mutation-dependent recognition site for the Hincll restriction endonuclease. The digestion of the resulting PCR product (285 base pairs) with Hincll would generate two fragments of, respectively, 26 and 259 base pairs only in the presence of the $1907 T>$ G mutation. Panel a: a pedigree describing a part of the kindred and the occurrence of adFNDI. Clinically affected subjects are indicated by filled symbols, unaffected subjects are indicated by open symbols, and the subjects at risk for inheriting adFNDI are indicated by an open symbol with a question mark. Panel b: agarose gel electrophoresis analysis of the DNA fragments generated by Hincll digestion of the PCR-amplified exon 2 from the family members indicated in panel a. The 259 base pair fragment was apparent in all the affected subjects, not in any unaffected members, and in the subjects at risk for inheriting adFNDI fully verifying the sequencing results. UC, uncleaved PCR amplified exon 2.

Norwegian kindred, ${ }^{17}$ and finally, the $1883 \mathrm{G}>\mathrm{T}$ (G96C) mutation identified in an American kindred. ${ }^{17}$

In one kindred (Table 1, kindred 5), a mutation was identified in an unaffected 1-year-old child at risk for inheriting adFNDI (Figures 1 and 2). In three kindreds (Table 1, kindreds 3-4 and Table 2, kindred 15), a mutation was identified in, respectively, a newborn and two 2.5-yearold children without any clinical assessment, but at risk for inheriting adFNDI. In two other children, both newborn and also without any clinical assessment, no mutations were identified (Table 2, kindreds 10 and 13).

\section{Discussion}

By examining a total of 38 kindreds in which adFNDI appear to be segregating, we have now identified 24 different mutations in the AVP gene. ${ }^{1,3,9,12,17,34,39}$ Although the total number of unaffected subjects included in the present study was small and although no formal linkage analysis was performed to prove that the mutations identified actually cause adFNDI, their absence among 296 normal alleles from 40 healthy controls, ${ }^{17} 10$ patients with idiopathic NDI, ${ }^{40}$ and at least 98 healthy relatives in 
kindreds with a family history of adFNDI ${ }^{8-15,17}$ support the assumption the each of the mutations causes adFNDI in the kindred in whom it was identified. This is even further supported by the fact that each mutation identified is the only one present in the AVP gene, they all predict a change in the amino-acid sequence of the AVP pre-prohormone, and all but one affects codons that are affected by other mutations previously shown to cause the disease (see below and Figure 3).

One interesting finding in the present study is the probable incomplete penetrance of the mutation predicting the V67A (NP36) amino-acid substitution (Table 1, kindred 3). The unusual family history of the kindred (see Materials and methods), if correct, suggests that the

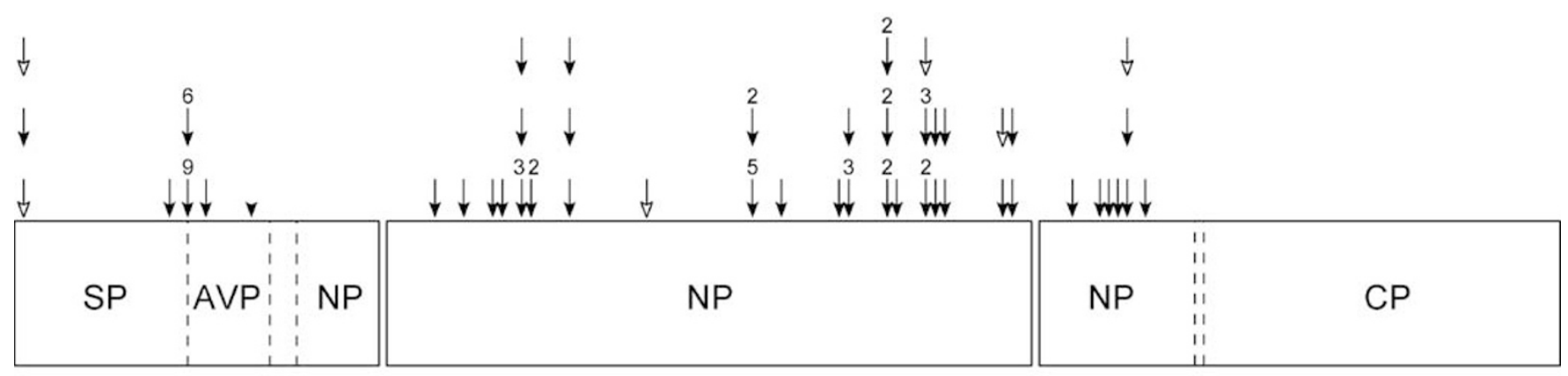

Exon 1

Exon 2

Exon 3

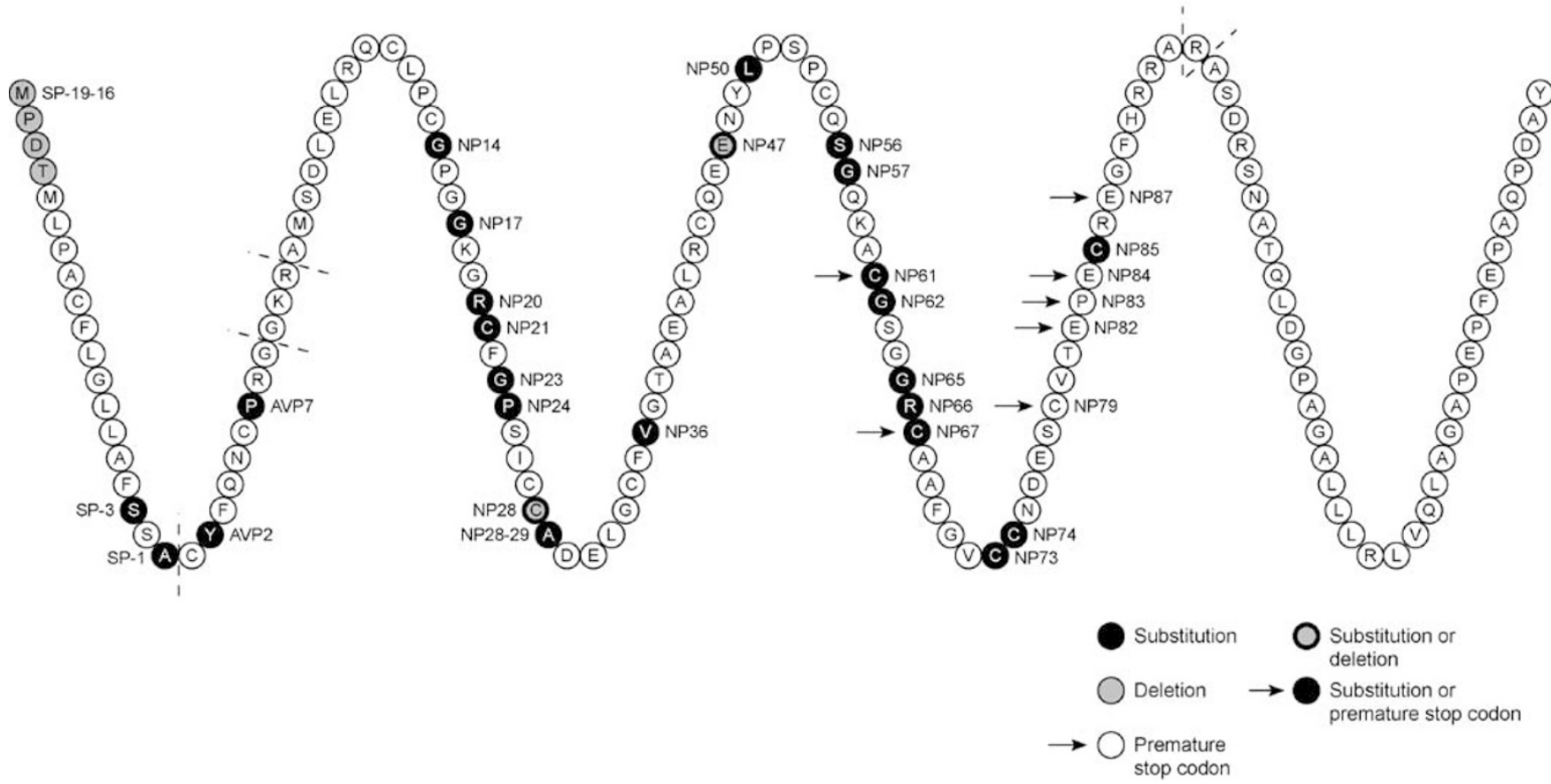

Figure 3 Schematic structure of the AVP gene (upper panel) and the AVP pre-prohormone (lower panel). The location in the AVP gene of the novel mutations associated with adFNDI identified in the present study are shown by open arrows, previously published mutations associated with adFNDI ${ }^{8-15}$ are shown by filled arrows, and a mutation associated with recessive inheritance of $\mathrm{FNDI}^{57}$ is shown by an arrowhead. Each arrow represents a single unique mutation. Numbers above the arrows indicate the number of apparently unrelated adFNDI kindreds identified to carry the same mutation. No number above an arrow indicates that only a single adFNDI kindred has been identified to carry the specific mutation. The deduced consequence of these mutations at the protein level is shown in the AVP pre-prohormone primary structure by symbols indicating: amino-acid substitutions, filled circles; amino-acid deletions, shaded circles; premature stop codons, open circles with arrows; substitutions or deletions, shaded circles with filled frames; substitutions or premature stop codons, filled circles with arrows. Numbers refer to the amino-acid position in the individual peptides originating from the AVP pre-prohormone and the abbreviations are: SP, signal peptide; AVP, arginine vasopressin; NP, neurophysin II; and CP, copeptin. Dashed bars indicate the cleavage sites for the enzymes responsible for AVP pre-prohormone processing (also indicated in the AVP gene structure). The NP74 and NP84 mutations were originally published as NP73 ${ }^{13}$ and NP83, respectively. ${ }^{10}$ 
proband inherited the mutation through his mother and maternal grandmother in whom it thus appeared to have been nonpenetrant or that his mother inherited the mutation from another male relative who was not the father of record. Since only two subjects, one affected and a newborn without clinical assessment, were studied, it is difficult to correlate the genotype and phenotype in the kindred. A more thorough clinical and genetic evaluation is indicated. The mutation is remarkable in that it affects a region of NP, not affected by any other mutations so far (Figure 3). It is predicted to produce only a minor change from a hydrophobic valine residue V67 (NP36) to the smaller, but also hydrophobic alanine residue. It can be speculated that this amino-acid substitution as a result of its location in the interface between the individual NP monomers ${ }^{18,41}$ and although representing only a minor change may interfere with dimerization, rather than the initial folding of the AVP prohormone. It has not been possible to examine in detail whether the clinical phenotype resulting from this mutation diverges from the classical adFNDI phenotype.

The identification of six novel and seven different recurrent mutations in the AVP gene in 15 previously unreported kindreds with diabetes insipidus in the present study both confirms and further extends the mutation pattern that has emerged from previous observations in kindreds with adFNDI (Figure 3 ). It suggests that mutations in the AVP gene associated with adFNDI affect amino-acid residues known or reasonably presumed to be important for proper folding and/or dimerization of the NP moiety of the AVP prohormone. ${ }^{17,18}$ The $225 \mathrm{~A}>\mathrm{G}$ and $227 \mathrm{G}>\mathrm{A}$ mutations identified (Table 1, kindreds 1 and 2) change a nucleotide in the translation initiation codon of the AVP gene. The effect of a similar mutation, 227delG, identified in a Swiss adFNDI kindred ${ }^{42}$ also changing the translation initiation codon has been examined by in vitro translation experiments. ${ }^{25}$ Apparently, it results in the deletion of the first four amino-acid residues of the signal peptide (M1_T4del) due to alternative initiation of translation at a second, in-frame ATG present four codons downstream. The heterologous expression of the 227delG mutation in COS-7 cells further indicates that the apparently truncated signal peptide is functional for targeting and translocation into the ER, but is markedly resistant to cleavage by signal peptidase. $^{25}$ Since the mutated AVP prohormone was retained in the ER and disulfide-linked aggregates were observed, it was suggested that the uncleaved signal peptide containing a cysteine residue somehow interferes with the formation of the C20-C25 disulfide bridge in the AVP moiety of the prohormone. This is likely to affect the proper folding and subsequent dimerization of individual NP molecules, since these processes seem to require the insertion of the cyclic disulfide linked N-terminal domain of the AVP moiety into the hormone-binding pocket of NP. ${ }^{41,43-48}$ Impaired signal peptide processing and cellular trafficking has also been described for another adFNDI mutation, ${ }^{27,33}$ predicting an A19T (SP-1) amino-acid substitution of a residue known to be very critical for the signal peptidase activity. ${ }^{49}$

The other novel mutations identified (Table 1, kindreds 4-6) are deduced to eliminate either glycine, G96D (NP65) or cysteine residues, C104G (NP73) and C116W (NP85), located in the NP domain of the AVP porhormone. Other mutations affecting these amino-acid residues have been described previously in adFNDI kindreds, namely $1883 \mathrm{G}>\mathrm{T}$ (G96C) in an American kindred, ${ }^{17} 1884 \mathrm{G}>\mathrm{T}$ (G96V) in both a German and two Japanese kindreds, ${ }^{50-52}$ 1908G $>$ T $(\mathrm{C} 104 \mathrm{~F})$ in an American kindred, ${ }^{14}$ as well as $2110 \mathrm{~T}>\mathrm{G} \quad(\mathrm{C} 116 \mathrm{G})^{8}$ and $2110 \mathrm{~T}>\mathrm{C} \quad(\mathrm{C} 116 \mathrm{R})^{53}$ in two Dutch kindreds. They are known to be essential for the $\mathrm{NP}$ molecule to form a stable three-dimensional structure, ${ }^{54}$ the glycine residues by conferring flexibility to the protein backbone and the cysteine residues by forming intrachain disulfide bridges between NP73 and NP61 as well as between NP85 and NP67. The cellular effects of the G96D (NP65) substitution are probably similar to those of the G96V substitution that has been investigated by heterologous expression in different cell lines. ${ }^{26}$ It seems to cause severe impairment of the AVP prohormone processing and secretion probably due to an almost complete retention in the ER. Since the G96 residue is located in one of the eight internal $\beta$-sheets of the NP domain, it could possible play an essential role in the proper folding of the AVP prohormone. Severe effects on the cellular handling of the AVP prohormone have also been observed for the C116G (NP85) substitution, ${ }^{30}$ which is comparable to the $\mathrm{C} 116 \mathrm{~W}$ substitution deduced to result from one of the mutations identified in the present study. Since no disulfide-linked mutant AVP prohormone was detected in the cells expressing this mutation, ${ }^{30}$ it was suggested that the ER retention was caused by incomplete folding of the NP moiety and not by dimerization of the AVP prohormone via its unpaired cysteine residues. Whether adFNDI mutations resulting in either elimination or addition of cysteine residues to the NP moiety of the prohormone share a common mechanism of ER retention still remains unknown.

The seven different previously described mutations identified in nine kindreds in the present study affect, respectively, the signal peptide (A19T and A19V (SP-1)), glycine residues (G54R (NP23), and G96C (NP65)), the AVP-binding pocket in NP ( $\triangle \mathrm{E} 78$ and E78G (NP47)), as well as a cysteine residue by the formation of a premature stop codon (C92X (NP61)). Although these mutations, as well as those identified previously, affect amino-acid residues throughout the AVP pre-prohormone, they do not distribute randomly but tend to cluster in specific regions especially affecting the signal peptide, the central conserved region of NP as well as in the hormone-binding pocket (Figure 3). Three of these, namely those predicting 
the A19T (SP-1) and A19V (SP-1) substitutions as well as that predicting the $\Delta \mathrm{E} 78$ (NP47) deletion are now by far the most common adFNDI mutations, identified in respectively, nine, six, and five kindreds. The E78 amino-acid residue is additionally affected by another mutation, identified in two unrelated kindreds so far, predicting an E78G (NP47) substitution. Since each of them has been identified in kindreds of different race and/or nationality and since the kindreds had no known relationship to each other, they probably arose independently. However, it is not possible to exclude a common progenitor for, for example, the mutations identified in both Caucasian American and Danish kindreds. The ratio of recurrent mutations identified in the present study $9 / 15(=60 \%)$ is significantly higher than the $4 / 17$ (=23.5\%) identified in one of our previous studies. ${ }^{17}$ This could reflect the fact that the adFNDI mutation spectrum is now almost revealed.

In the present study, mutations were identified in an asymptomatic 1-year-old child (Table 1, kindred 5) and in three children under the age of 3 years without any clinical assessment (Table 1, kindreds 3-4 and Table 2, kindred 15), all at risk for inheriting adFNDI. To our knowledge, at least one of these children (Table 1, kindred 4) has developed DI symptoms meanwhile. In two other children, both newborn also without any clinical assessment, no mutations were identified (Table 2, kindreds 10 and 13). A preclinical diagnosis like this promotes early clarification concerning the disease often resulting in the relief of parental concern. Thus, although not contributing directly in clarifying the mechanism underlying the development of the disease, the identification of mutations in kindreds in which adFNDI is segregating not only seems to provide a basis for a genuine insight into the structural requirements for proper AVP prohormone folding in the ER, but also enables valuable genetic counseling.

\section{Acknowledgements}

We thank the following persons sincerely for their contribution to the study: Norbert Albers, Zentrum für Kinderheilkunde der Universität Bonn, Bonn; Michael Croxson, Auckland Hospital, Auckland; Cordula Gamm, Altonaer Kinderkrankenhaus, Hamburg; Václav Hána, Charles University, Prague; Gert Matthijs, Katholieke Universiteit Leuven, Leuven; Patrizia Matarazzo, University of Torino, Torino; K Sinko-Sanz, Universitätsklinik für Kinder- und Jugendheilkunde, Vienna; Dag Veimo, Nordland Sentralsykehus, Bodø; Franz Waldhauser, Universitätsklinik für Kinder- und Jugendheilkunde, Vienna; and Otto Westphal, Barn och Ungdoms Sjukhus, Göteborg. Last but not the least, we also thank Jane Hagelskjoer Knudsen for her skilled laboratory assistance. This work was supported by grants from the Novo Nordic Foundation and the University of Aarhus, Denmark.

\section{References}

1 Hansen LK, Rittig S, Robertson GL: Genetic basis of familial neurohypophyseal diabetes insipidus. Trends Endocrinol Metab 1997; 8: 363-372.

2 Robertson GL: Diabetes insipidus. Endocrinol Metab Clin North Am 1995; 24: 549-572.
3 McLeod JF, Kovacs L, Gaskill MB, Rittig S, Bradley GS, Robertson GL: Familial neurohypophyseal diabetes insipidus associated with a signal peptide mutation (see comments). J Clin Endocrinol Metab 1993; 77: 599A-599G.

4 Mahoney CP, Weinberger E, Bryant C, Ito M, Jameson JL, Ito M: Effects of aging on vasopressin production in a kindred with autosomal dominant neurohypophyseal diabetes insipidus due to the DeltaE47 neurophysin mutation. J Clin Endocrinol Metab 2002; 87: 870-876.

5 Green JR, Buchan GC, Alvord ECJ, Swanson AG: Hereditary and idiopathic types of diabetes insipidus. Brain 1967; 90: 707-714.

6 Braverman LE, Mancini JP, McGoldrick DM: Hereditary idiopathic diabetes insipidus. A case report with autopsy findings. Ann Intern Med 1965; 63: 503-508.

7 Bergeron C, Kovacs K, Ezrin C, Mizzen C: Hereditary diabetes insipidus: an immunohistochemical study of the hypothalamus and pituitary gland. Acta Neuropathol 1991; 81: 345-348.

8 van den Akker EL, de Groot MR, Abbes AP, Bruggeman EJ, Franken AA, Engel H: Identification of a new mutation (CysII6Gly) in a family with neurogenic diabetes insipidus. Ned Tijdschr Geneeskd 2000; 144: 941-945.

9 Goking NQ, Chertow BS, Robertson GL, Rittig S, Siggaard C, Pedersen EB: A novel AVP-neurophysin gene mutation in familial neurohypophyseal diabetes insipidus presenting with nocturnal enuresis. J Endocr Genet 2001; 2: 105-113.

10 Bullmann C, Kotzka J, Grimm T et al: Identification of a novel mutation in the arginine vasopressin-neurophysin II gene in familial central diabetes insipidus. Exp Clin Endocrinol Diabetes 2002; 110: 134-137.

11 Kanemitsu N, Kawauchi A, Nishida M et al: Familial central diabetes insipidus detected by nocturnal enuresis. Pediatr Nephrol 2002; 17: 1063-1065.

12 Rittig S, Siggaard C, Ozata M et al: Autosomal dominant neurohypophyseal diabetes insipidus due to substitution of histidine for tyrosine(2) in the vasopressin moiety of the hormone precursor. J Clin Endocrinol Metab 2002; 87: 3351-3355.

13 Rutishauser J, Kopp P, Gaskill MB, Kotlar TJ, Robertson GL: Clinical and molecular analysis of three families with autosomal dominant neurohypophyseal diabetes insipidus associated with a novel and recurrent mutations in the vasopressin-neurophysin II gene. Eur J Endocrinol 2002; 146: 649-656.

14 Santiprabhob J, Browning J, Repaske D: A missense mutation encoding Cys73Phe in neurophysin II is associated with autosomal dominant neurohypophyseal diabetes insipidus. Mol Genet Metab 2002; 77: 112-118.

15 Boson WL, Sarubi JC, D'Alva CB et al: A signal peptide mutation of the arginine vasopressin gene in monozygotic twins. Clin Endocrinol (Oxf) 2003; 58: 108-110.

16 Sausville E, Carney D, Battey J: The human vasopressin gene is linked to the oxytocin gene and is selectively expressed in a cultured lung cancer cell line. J Biol Chem 1985; 260: 10236-10241.

17 Rittig S, Robertson GL, Siggaard C et al: Identification of 13 new mutations in the vasopressin-neurophysin II gene in 17 kindreds with familial autosomal dominant neurohypophyseal diabetes insipidus. Am J Hum Genet 1996; 58: 107-117.

18 Eubanks S, Nguyen TL, Deeb R, Villafania A, Alfadhli A, Breslow E: Effects of diabetes insipidus mutations on neurophysin folding and function. J Biol Chem 2001; 276: 29671-29680.

19 Hammond C, Helenius A: Quality control in the secretory pathway: retention of a misfolded viral membrane glycoprotein involves cycling between the ER, intermediate compartment, and Golgi apparatus. J Cell Biol 1994; 126: 41-52.

20 Trombetta ES, Helenius A: Lectins as chaperones in glycoprotein folding. Curr Opin Struct Biol 1998; 8: 587-592.

21 Ellgaard L, Molinari M, Helenius A: Setting the standards: quality control in the secretory pathway. Science 1999; 286: 1882-1888.

22 Robertson GL, Rittig S, Gu WX et al: Pathogenesis and pathophysiology of familial neurohypophyseal diabetes insipidus; in Saito T, Kurokawa K, Yoshida $\mathrm{S}$ (eds): 
Neurohypophysis: recent progress of vasopressin and oxytocin research. Amsterdam: Elsevier Science B.V., 1995, pp 593-603.

23 Ito M, Jameson JL: Molecular basis of autosomal dominant neurohypophyseal diabetes insipidus. Cellular toxicity caused by the accumulation of mutant vasopressin precursors within the endoplasmic reticulum. J Clin Invest 1997; 99: 1897-1905.

24 Olias G, Richter D, Schmale H: Heterologous expression of human vasopressin-neurophysin precursors in a pituitary cell line: defective transport of a mutant protein from patients with familial diabetes insipidus. DNA Cell Biol 1996; 15: 929-935.

25 Beuret N, Rutishauser J, Bider MD, Spiess M: Mechanism of endoplasmic reticulum retention of mutant vasopressin precursor caused by a signal peptide truncation associated with diabetes insipidus. J Biol Chem 1999; 274: 18965-18972.

26 Nijenhuis M, Zalm R, Burbach JP: Mutations in the vasopressin prohormone involved in diabetes insipidus impair endoplasmic reticulum export but not sorting. I Biol Chem 1999; 274: 21200-21208.

27 Siggaard C, Rittig S, Corydon TJ et al: Clinical and molecular evidence of abnormal processing and trafficking of the vasopressin preprohormone in a large kindred with familial neurohypophyseal diabetes insipidus due to a signal peptide mutation. J Clin Endocrinol Metab 1999; 84: 2933-2941.

28 Nijenhuis M, Zalm R, Burbach JP: A diabetes insipidus vasopressin prohormone altered outside the central core of neurophysin accumulates in the endoplasmic reticulum. Mol Cell Endocrinol 2000; 167: 55-67.

29 Si-Hoe S, de Bree FM, Nijenhuis M et al: Endoplasmic reticulum derangement in hypothalamic neurons of rats expressing a familial neurohypophyseal diabetes insipidus mutant vasopressin transgene. FASEB J 2000; 14: 1680-1684.

30 Nijenhuis $\mathrm{M}$, van den Akker EL, Zalm $\mathrm{R}$ et al: Familial neurohypophysial diabetes insipidus in a large Dutch kindred: effect of the onset of diabetes on growth in children and cell biological defects of the mutant vasopressin prohormone. J Clin Endocrinol Metab 2001; 86: 3410-3420.

31 Davies J, Murphy D: Autophagy in hypothalamic neurones of rats expressing a familial neurohypophysial diabetes insipidus transgene. J Neuroendocrinol 2002; 14: 629-637.

32 Yuasa $\mathrm{H}$, Ito $\mathrm{M}$, Nagasaki $\mathrm{H}$ et al: Glu-47, which forms a salt bridge between neurophysin-II and arginine vasopressin, is deleted in patients with familial central diabetes insipidus (see comments). J Clin Endocrinol Metab 1993; 77: 600-604.

33 Ito M, Oiso Y, Murase T et al: Possible involvement of inefficient cleavage of preprovasopressin by signal peptidase as a cause for familial central diabetes insipidus. J Clin Invest 1993; 91: 2565-2571.

34 Rittig S, Kovacs L, Gregersen N, Robertson GL: Familial neurogenic diabetes insipidus in 5 Danish kindreds; in Gross P, Richter D, Robertson GL (eds): Vasopressin. Paris: John Libbey Eurotext, 1993, pp 600.

35 Repaske DR, Summar ML, Krishnamani MR et al.: Recurrent mutations in the vasopressin-neurophysin II gene cause autosomal dominant neurohypophyseal diabetes insipidus. J Clin Endocrinol Metab 1996; 81: 2328-2334.

36 Calvo B, Bilbao JR, Urrutia I, Eizaguirre J, Gaztambide S, Castano L: Identification of a novel nonsense mutation and a missense substitution in the vasopressin-neurophysin II gene in two Spanish kindreds with familial neurohypophyseal diabetes insipidus. J Clin Endocrinol Metab 1998; 83: 995-997.

37 Repaske DR, Medlej R, Gultekin EK et al: Heterogeneity in clinical manifestation of autosomal dominant neurohypophyseal diabetes insipidus caused by a mutation encoding Ala- $1 \rightarrow$ Val in the signal peptide of the arginine vasopressin/neurophysin II/ copeptin precursor. J Clin Endocrinol Metab 1997; 82: 51-56.

38 Heppner C, Kotzka J, Bullmann C, Krone W, Muller-Wieland D: Identification of mutations of the arginine vasopressinneurophysin II gene in two kindreds with familial central diabetes insipidus. J Clin Endocrinol Metab 1998; 83: 693-696.

39 Mundschenk J, Rittig S, Siggaard C, Hensen J, Lehnert H: A new mutation of the arginine vasopressin-neurophysin II gene in a family with autosomal dominant neurohypophyseal diabetes insipidus. Exp Clin Endocrinol Diabetes 2001; 109: 406-409.

40 Ito M, Mori Y, Oiso Y, Saito H: A single base substitution in the coding region for neurophysin II associated with familial central diabetes insipidus. J Clin Invest 1991; 87: 725-728.

41 Chen LQ, Rose JP, Breslow E et al: Crystal structure of a bovine neurophysin II dipeptide complex at 2.8 A determined from the single-wavelength anomalous scattering signal of an incorporated iodine atom. Proc Natl Acad Sci USA 1991; 88: $4240-4244$

42 Rutishauser J, Boni-Schnetzler M, Boni J et al: A novel point mutation in the translation initiation codon of the pre- provasopressin-neurophysin II gene: cosegregation with morphological abnormalities and clinical symptoms in autosomal dominant neurohypophyseal diabetes insipidus. J Clin Endocrinol Metab 1996; 81: 192-198.

43 Nicolas P, Batelier G, Rholam M, Cohen P: Bovine neurophysin dimerization and neurohypophyseal hormone binding. Biochemistry 1980; 19: 3565-3573.

44 Kanmera T, Chaiken IM: Molecular properties of the oxytocin/ bovine neurophysin biosynthetic precursor. Studies using a semisynthetic precursor. J Biol Chem 1985; 260: 8474-8482.

45 Breslow E, Burman S: Molecular, thermodynamic, and biological aspects of recognition and function in neurophysinhormone systems: a model system for the analysis of proteinpeptide interactions. Adv Enzymol Relat Areas Mol Biol 1990; 63: $1-67$.

46 Rose JP, Wu CK, Hsiao CD, Breslow E, Wang BC: Crystal structure of the neurophysin-oxytocin complex. Nat Struct Biol 1996; 3: $163-169$.

47 de Bree FM, Burbach JP: Structure-function relationships of the vasopressin prohormone domains. Cell Mol Neurobiol 1998; 18: 173-191.

48 Kim PS, Arvan P: Endocrinopathies in the family of endoplasmic reticulum (ER) storage diseases: disorders of protein trafficking and the role of ER molecular chaperones. Endocr Rev 1998; 19: $173-202$.

49 von Heijne G: The signal peptide. J Membr Biol 1990; 115: 195201.

50 Rauch F, Lenzner C, Nurnberg P, Frommel C, Vetter U: A novel mutation in the coding region for neurophysin-II is associated with autosomal dominant neurohypophyseal diabetes insipidus. Clin Endocrinol (Oxf) 1996; 44: 45-51.

51 Ueta Y, Taniguchi S, Yoshida A et al: A new type of familial central diabetes insipidus caused by a single base substitution in the neurophysin II coding region of the vasopressin gene. J Clin Endocrinol Metab 1996; 81: 1787-1790.

52 Kubota T, Yamamoto T, Ozono K, Shimotsuji T: Hyperintensity of posterior pituitary on MR T1WI in a boy with central diabetes insipidus caused by missense mutation of neurophysin II gene. Endocr J 2001; 48: 459-463.

53 Abbes AP, Bruggeman B, van den Akker EL et al: Identification of two distinct mutations at the same nucleotide position, concomitantly with a novel polymorphism in the vasopressinneurophysin II gene (AVP-NP II) in two Dutch families with familial neurohypophyseal diabetes insipidus. Clin Chem 2000; 46: $1699-1702$.

54 Breslow E: Structure and folding properties of neurophysin and its peptide complexes: biological implications. Regul Pept 1993; 45: $15-19$.

55 Antonarakis SE: Recommendations for a nomenclature system for human gene mutations. Nomenclature Working Group. Hum Mutat 1998; 11: 1-3.

56 den Dunnen JT, Antonarakis SE: Mutation nomenclature extensions and suggestions to describe complex mutations: a discussion. Hum Mutat 2000; 15: 7-12.

57 Willcutts MD, Felner E, White PC: Autosomal recessive familial neurohypophyseal diabetes insipidus with continued secretion of mutant weakly active vasopressin. Hum Mol Genet 1999; 8: $1303-1307$. 